\title{
LETTER
}

Immunotherapy

\section{Low-dose ruxolitinib plus steroid in severe SARS-CoV-2 pneumonia}

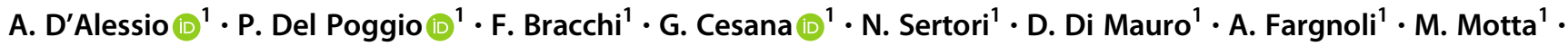 \\ C. Giussani ${ }^{1} \cdot$ P. Moro ${ }^{1} \cdot$ G. Vitale ${ }^{2} \cdot$ M. Giacomini ${ }^{2} \cdot$ G. Borra ${ }^{3}$
}

Received: 25 June 2020 / Revised: 31 July 2020 / Accepted: 27 October 2020 / Published online: 10 November 2020

(c) Springer Nature Limited 2020. This article is published with open access

\section{To the Editor:}

SARS-CoV-2 is a biphasic illness characterized by a first flu-like phase, followed by a pulmonary and systemic disease, in which a dysregulated cytokine storm may lead to acute respiratory distress (ARDS) and death [1]. JAK-STAT inhibitors block the common pathway of cytokine activation, may reduce the over-exuberant inflammatory reaction and decrease mortality [2, 3].

Ruxolitinib is a JAK 1 and 2 (Janus Kinase) inhibitor used in the treatment of myelofibrosis, policytemia vera and hemophagocytic lymphohistiocytosis, which is characterized by a cytokine derangement similar to what observed in SARS-CO-V2 infection [4].

We performed a non-randomized clinical study on the effect of ruxolitinib in patients with severe COVID-19 pneumonia not requiring mechanical ventilation at baseline (group A), comparing them to a control group of patients with the same clinical and radiological characteristics and hospitalized in the same time period (group B). All patients over age 18, admitted to our Hospital from March 13, 2020 to April 13, 2020 and eligible to ruxolitinib Managed Access Plan (MAP) were evaluated. The MAP program for ruxolitinib was registered by Novartis (https://clinicaltrials. gov/ct2/show/NCT04337359), approved by the Italian Ministry of Health and by the ethical review board of our institution. Inclusion criteria were a nasopharyngeal swab

$\triangle$ P. Del Poggio

paolo.delpoggio51@gmail.com

1 COVID Medical Department, Policlinico S.Marco Gruppo San Donato University and Research Hospital, Zingonia, Bergamo, Italy

2 Intensive Care Unit, Policlinico S.Marco Gruppo San Donato University and Research Hospital, Zingonia, Bergamo, Italy

3 Policlinico S.Marco Gruppo San Donato University and Research Hospital, Zingonia, Bergamo, Italy positive for SARS-CoV2 by polymerase chain reaction, pulmonary infiltrates typical for interstitial pneumonia on Chest CT and respiratory frequency $>30 / \mathrm{min}$ or oxygen saturation equal or lower than $93 \%$. We excluded patients with chronic comorbidities or neoplastic disease with $<1$ year life expectancy, documented bacterial superinfections, advanced dementia, previous treatment with anti-interleukin 1 or anti-interleukin 6 inhibitors. Ruxolitinib was administered orally at a dose of $5 \mathrm{mg}$ twice daily for 7 days and then tapered to $5 \mathrm{mg}$ daily to complete a 10-day course of treatment. In addition to ruxolitinib all patients received methyl-prednisolone $1 \mathrm{mg} / \mathrm{kg}$ intravenously for 3 days followed by $0.5 \mathrm{mg} / \mathrm{kg}$ for 5 days and then oral prednisone, which was slowly tapered in the course of 2 weeks. Concomitant antiviral therapy such as hydroxychloroquine, lopinavir/ritonavir, remdesivir was not permitted during treatment with ruxolitinib. The control group was chosen among the patients admitted to our hospital in the same period for COVID-19 pneumonia and hospitalized in a ward with the same intensity of care and who did not apply for Ruxolitinib MAP. Both treated and control groups were comparable, with the exception of comorbidities, which were slightly over-represented in the control group, although not significantly (Table 1). Primary outcomes were defined as clinical recovery without mechanical ventilation, admission to ICU for mechanical ventilation and death. Patients were considered clinically recovered if they had been afebrile for at least 3 days before hospital discharge and with an oxygen saturation of at least $95 \%$. Both overall survival and survival free of unwanted outcomes-i.e., death and ICU admission-were evaluated as intention to treat by means of Kaplan-Meyer analysis. As a secondary outcome we considered a reduction of the inflammatory response, defined as absence of fever and at least a $30 \%$ decrease of CRP levels at the second clinical observationi.e., 3-10 days after hospital admission. Patients were censored at the time of live discharge from the hospital. Statistical analysis was performed with MedCalc software (18.11.6 version). 
Table 1 Baseline characteristics of the patients.

\begin{tabular}{|c|c|c|c|}
\hline & Group A (32) & Group B (43) & $p$ \\
\hline Mean age in years ( $95 \%$ C.I.) & $67.5(63-71)$ & $67.8(64-71)$ & $p=0-65^{\wedge}$ \\
\hline Male Sex $n(\%)$ & $22(69)$ & $30(69)$ & $p=1.00^{*}$ \\
\hline Mean BMI $( \pm$ SD $)$ & $25.4(3.74)$ & $25.03(3.42)$ & $p=0.37^{\wedge}$ \\
\hline \multicolumn{4}{|l|}{ Oxygen support (on admission) } \\
\hline None $n .(\%)$ & $11(34)$ & $16(37)$ & $p=0.80^{*}$ \\
\hline Low flow oxygen $(<101 / \mathrm{min})$ & $6(19)$ & $5(11)$ & \\
\hline High flow oxygen (>10 1/min) & $15(47)$ & $22(51)$ & \\
\hline \multicolumn{4}{|l|}{ Coexisting conditions } \\
\hline Any condition $\mathrm{n}(\%)$ & $15(47)$ & $25(58)$ & $p=0.33^{*}$ \\
\hline Hypertension & $15(47)$ & $20(46)$ & \\
\hline Diabetes & $4(13)$ & $8(18)$ & \\
\hline Others & & $4(9)$ & \\
\hline \multicolumn{4}{|l|}{ Chest CT n (\%) } \\
\hline$<50 \%$ lung involvement & $17(53)$ & $20(46)$ & $p=0.57^{*}$ \\
\hline$>50 \%$ lung involvement & $15(47)$ & $23(53)$ & \\
\hline \multicolumn{4}{|l|}{ Median laboratory values: } \\
\hline Oxygen saturation $\%$ (median and $95 \%$ C.I) & $91.7(90-92)$ & $91.9(91-92)$ & $p=0.29^{\wedge \wedge}$ \\
\hline Creatinine $\mathrm{mg} / \mathrm{dL}$ (median and 95\% C.I.) & $1.2(1.09-1.30)$ & $1.2(1.0-1.43)$ & $p=0.75^{\wedge \wedge}$ \\
\hline PCR $\mathrm{mg} / \mathrm{dL}^{\S}$ (median and $95 \%$ C.I.) & $14.2(7.8-17.9)$ & $12.2(10-15.1)$ & $p=0.90^{\wedge \wedge}$ \\
\hline D-Dimer ${ }^{\S \S} \mathrm{ng} / \mathrm{ml}$ (median and 95\% C.I.) & $1.3(0.83-1.92)$ & $1.07(0.70-1.70)$ & $p=0.65^{\wedge \wedge}$ \\
\hline Total Lymphocyte count $\left(\mathrm{x} \quad 10^{3}\right)$ & $0.9(0.65-1-0)$ & $0.9(0.7-1.1)$ & $p=0.77^{\wedge} \wedge$ \\
\hline \multicolumn{4}{|l|}{ ISTH-SIC score** No $(\%)$} \\
\hline 0 & $21(66)$ & $26(60)$ & $(0+1$ vs 2$) p=1.00^{*}$ \\
\hline 1 & $10(31)$ & $14(32)$ & \\
\hline 2 & $1(3)$ & $2(5 \%)$ & \\
\hline $3-4$ & - & - & \\
\hline
\end{tabular}

${ }^{*}$ Chi Square ${ }^{\wedge}$ Student $t$ test ${ }^{\wedge}$ Mann-Whitney rank-sum test ${ }^{\S}$ normal values $<0.5 \mathrm{mg} / \mathrm{dL}^{\S}$ normal values $<0.4 \mathrm{ng} / \mathrm{ml}$.

** International Society of Thrombosis and Haemostasis Sepsis Induced Coagulation Score [Iba et al. J Thromb Haemost. 2019; 17(11):1989-1994].
Among the 93 patients admitted from March 13 to April 13, $32(35 \%)$ were enrolled into the MAP program for ruxolitinib, $43(46 \%)$ served as a control group and 18 (19\%) were excluded from the analysis because they did not meet the inclusion criteria of this study. During the hospitalization 23 patients of group B $(67 \%)$ received hydroxychloroquine, $13(30 \%)$ both hydroxycloroquine and lopinavir/ritonavir and, $11(25 \%)$ methyl-prednisolone at the dose of $0.5-1 \mathrm{mg} / \mathrm{kg}$ for 3-10 days. Two patients of group A $(6.3 \%)$ and three of group B (6.9\%) received enoxaparin at the therapeutic dose of $100 \mathrm{IU} / \mathrm{Kg}$ twice a day, all the other patients were treated prophylactically with $100 \mathrm{IU} / \mathrm{kg}$ daily.

At the end of the study, all patients had reached the established endpoints. Twenty-four patients of group A (75\%) were considered clinically recovered without admission to the ICU, five (16\%) were transferred to the ICU, mechanically ventilated and clinically cured and three patients $(9 \%)$ died, one of whom in the ICU. Ruxolitinib was withdrawn in all five patients admitted to the ICU, while steroid was continued as initially planned. No rebound of inflammation was observed in these patients. On the contrary only 27 patients of group B (63\%) were considered clinically recovered, three $(7 \%)$ were transferred to the ICU and clinically cured and 13 died (30\%), three of whom in the ICU. Kaplan-Meyer estimates of the percentage of patients who were alive and clinically recovered at the end of follow-up were $89.1 \%(\mathrm{SE} \pm 10.3$ ) for group $\mathrm{A}$ and $57.1 \%$ for group $\mathrm{B}(\mathrm{SE} \pm 6.1)$, as represented in Fig. 1 $(p=0.0034)$. Likewise the percentage of patients free of unwanted outcome at the same time point was $45 \%$ (SE 16.4) for group A and 22.9\% (SE 17.2) for group B ( $p=$ $0.0052)$. The percentage of patients who reached the secondary endpoint was also significantly higher in the treated than in the control group: 28 patients of group A (87\%) vs 10 of group $\mathrm{B}(23 \%), p=0.0001$. At the second clinical observation median CRP levels decreased from 14.6 (range $1.8-30$ ) to 1.33 (range $0.05-22$ ) $\mathrm{mg} / \mathrm{dL}$ in group $\mathrm{A}$, while 


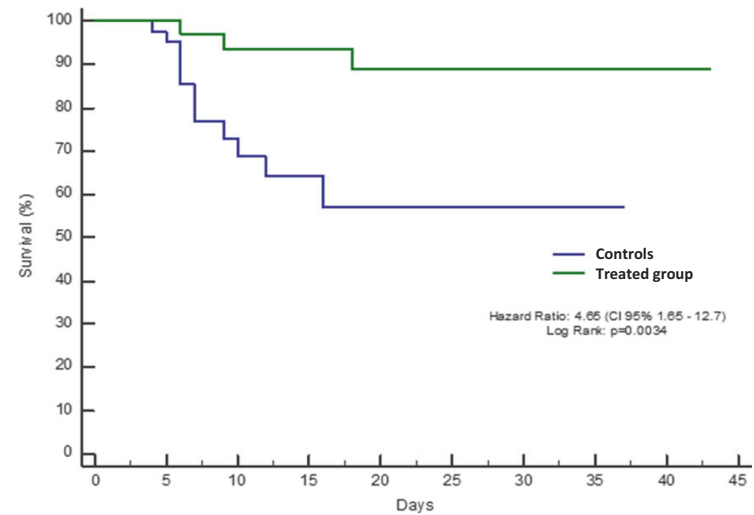

Number at Risk

Treated group 32

Controls 43
29

25
29

Fig. 1 Overall survival in patients with severe COVID-19 pneumonia treated with ruxolitinib plus steroid (group A) compared to controls (Group B): Kaplan Meyer curves. The day of hospitalization was considered as time 0 in the $y$ axis. Patients were censored at the time of live discharge from the hospital. No patient was lost at follow-up.

remained stable in group B: $11.53 \mathrm{mg}$ (range 1.8-29) and 12 (range $0.1-32$ ) $\mathrm{mg} / \mathrm{dL}$. The difference between the two groups was highly significant (Mann-Whitney Rank Sum test $p=0.0001)$. We did not observe any major adverse event related to the use of steroid nor to ruxolitinib.

The patients included in our study had severe, hypoxemic COVID-19 related pneumonia, were admitted to medical wards and yet did not require mechanical ventilation. These patients represent a "gray zone" in which a downregulation of the over-exuberant immunity may prevent the progression of lung damage and avoid intubation. The time window to start anti-inflammatory drugs is very important because an early administration could enhance viral replication, while a late treatment could exacerbate the immunological exhaustion caused by the prolonged cytokine storm. We used an association of steroid and a JAK-1 and 2 inhibitor (ruxolitinib) as immunomodulatory drugs. The rationale was to enhance the broad immunosuppressant effect of corticosteroids with a specific multi-cytokine inhibitor such as ruxolitinib. JAK-STAT signaling is involved in the intracellular pathways of many inflammatory proteins and its inhibition may lead to upstream downregulation of IL-6, TNF- $\alpha$, IL-1 $\beta$, IL-2, IL-8 [5]. This extended action could entail a better control of the hyperinflammatory syndrome than that achieved by single cytokine inhibitors like tocilizumab or anakinra. The use of a dual JAK1 and 2 inhibitor like ruxolitinib may also impact on $\mathrm{T}$ cell proliferation and activity, which play an important role in the cytokine storm, an effect mediated by the JAK-1 receptor and not achievable by selective JAK-2 inhibitors [6]. Our main concern with the use of JAK-STAT inhibitors

was the risk of enhancing viral replication and the occurrence of opportunistic infections, and for that reason we used half of the approved dose of ruxolitinib for hematologic diseases. JAK-STAT inhibitors may enhance viral replication by inhibiting interferon alpha production, but have also direct antiviral activity [7], although this effect can be achieved by ruxolitinib only at extremely high doses [8]. Baricitinib, another JAK1-2 inhibitor with stronger affinity for the AAK1 receptor down regulating Chlatryn mediated viral entry [8], has a greater antiviral activity and theoretically could be the drug of choice. However, it should be used with great caution in COVID-19 patients because of its propensity for arterial thrombosis [9]. COVID-19 related pneumonia is characterized by a severe pulmonary intravascular coagulopathy $[10,11]$ and the use of baricitinib could trigger or aggravate the immune mediated thrombosis.

We found a significant reduction in mortality and no significant adverse event in treated patients compared to controls. These favorable results were achieved through an attenuation of the systemic inflammatory response, since we detected a faster decline in CRP levels and disappearance of fever in treated patients. It is possible that steroids may have played a synergistic role with ruxolitinib in dampening the immune over-reactivity. In a recent large randomized trial steroids significantly reduced mortality in patients with COVID-19 pneumonia necessitating oxygen supplementation or mechanical intubation [12], but the reduction in mortality observed in our study with combination therapy was much greater. It is also worth noting that, in spite of a significant proportion of controls receiving steroids $(25 \%)$, the strength of the survival benefit was not weakened, suggesting that ruxolitinib was the most effective agent of the association. It should be explored in further randomized trials whether steroids provide real additive benefit to ruxolitinib or not. We are at the dawn of a new era in the treatment of COVID-19 and the proper timing, selection and judicious use of immunosuppressive drugs together with antiviral therapy $[13,14]$ could hopefully reduce the high death toll observed in this dreadful disease.

Acknowledgements We thank Mrs Maureen Naomi Quinn for language revision of the English text and Miss Sara Berva for data entering.

Author contributions $\mathrm{AD}, \mathrm{PD}, \mathrm{FB}$, and GC had full access to all the data and take responsibility for the integrity of the data in the study and the accuracy of their analysis. GC, SN, DD, FA, MM were responsible for the acquisition and interpretation of data. All members of the PSM ruxolitinib study group were responsible for the acquisition of data. PD drafted the manuscript. PD, GC, and FB performed the statistical analysis. GM and PM critically revised the manuscript and gave valuable suggestion for data analysis, $A D$ and $\mathrm{GB}$ supervised the study. 


\section{Compliance with ethical standards}

Conflict of interest The authors declare that they have no conflict of interest.

Publisher's note Springer Nature remains neutral with regard to jurisdictional claims in published maps and institutional affiliations.

Open Access This article is licensed under a Creative Commons Attribution 4.0 International License, which permits use, sharing, adaptation, distribution and reproduction in any medium or format, as long as you give appropriate credit to the original author(s) and the source, provide a link to the Creative Commons license, and indicate if changes were made. The images or other third party material in this article are included in the article's Creative Commons license, unless indicated otherwise in a credit line to the material. If material is not included in the article's Creative Commons license and your intended use is not permitted by statutory regulation or exceeds the permitted use, you will need to obtain permission directly from the copyright holder. To view a copy of this license, visit http://creativecommons. org/licenses/by/4.0/.

\section{References}

1. Raoult D, Zumla A, Locatelli F, Ippolito G, Kroemer G. Coronavirus infections: epidemiological, clinical and immunological features and hypotheses. Cell Stress. 2020. www.cell-stress.com, https://doi.org/10.15698/cst2020.04.2162.

2. La Rosée F, Bremer HC, Gerkke I, Kehr A, Hochaus A, Bimdt S, et al. The Janus Kinase 1-2 inhibitor ruxolitinib in COVID-19 with severe systemic hyperinflammation. Leukemia. 2020. https:// doi.org/10.1038/s41375-020-0891-0.

3. Cao Y, Zou L, Jiang T, Wang G, Chen L, Huang L, et al. Ruxolitinib in treatment of severe coronavirus disease 2019 (COVID19): a multicenter, single-blind randomized controlled trial. J Allergy Clin Immunol. 2020;146:137-46.
4. Wang J, Wang Y, Wu L, Wang X, Jin Z, Gao Z, et al. Ruxolitinib for refractory/relapsed hemophagocytic lymphohistiocytosis Haematologica. 2019. https://doi.org/10.3324/haematol.2019.222471.

5. Banerjee S, Biehl A, Gadina M, Hasni S, Schwartz D. JAK-STAT signaling as a target for inflammatory and autoimmune diseases: current and future prospects. Drugs. 2017;77:521-46.

6. Perner F, Schnider TM, Ranjan S, Wallescheck D, Ebert C, Pils $\mathrm{MC}$, et al. Specificity of JAK-kinase inhibition determines impact on human and murine T-cell function. Leukemia. 2016;30:991-5.

7. Carbone CJ, Zheng H, Bhattacharya S, Lewis JR, Reiter AM, Henthorn $\mathrm{P}$, et al. Protein tyrosine phosphatase $1 \mathrm{~B}$ is a key regulator of IFNAR1 endocytosis and a target for antiviral therapies. Proc Natl Acad Sci USA. 2012;109:19226-31.

8. Stebbing J, Phelan A, Griffin I, Tucker C, Oechsle O, Smith D, et al. COVID-19: combining antiviral and anti-inflammatory treatments Lancet Infect Dis. 2020. https://doi.org/10.1016/ S1473-3099(20)30132-8.

9. Smolen JS, Genovese MC, Takeuchi T, Hyslop DL, Macias W, Rooney T, et al. Safety profile of baricitinib in patients with active rheumatoid arthritis with over 2 years median time in treatment. J Rheumatol. 2019;46:7-18. http://www.jrheum.org/content/46/1/7.

10. McGonagle D, O’Donnell J, Sharif K, Emery P, Bridgewood C. Immune mechanisms of pulmonary intravascular coagulopathy in COVID-19 pneumonia. Lancet Rheumatol. 2020. https://doi.org/ 10.1016/S2665-9913(20)30121-1.

11. Bikdeli B, Madhavan MV, Jimenez D, Chuich T, Dreyfus I, Driggin E, et al. COVID-19 and thromboembolic disease: implications for prevention, antithrombotic therapy and follow- up. J Am Coll Cardiol. 2020;S0735-S1097:35008-7.

12. Horby $\mathrm{P}$ and The Recovery Collaborative Group. Dexamethasone in hospitalized patients with Covid-19-preliminary report. N Engl J Med. 2020. https://doi.org/10.1056/NEJMoa2021436.

13. Grein J, Ohmagari N, Shin D, Diaz G, Asperges E, Castagna A, et al. Compassionate use of remdesivir for patients with severe Covid-19. N Eng J Med. 2020. NEJMoa2007016. https://doi.org/ 10.1056/NEJMoa2007016.

14. Wang Y, Zhang D, Du G, Du R, Zhao J, Jin Y, et al. Remdesivir in adults with severe COVID- 19: a randomised, double-blind, placebo-controlled, multicentre trial. Lancet. 2020;395:1569-78. 